\title{
Analisis Sociomathematical Norms Peserta Didik dalam Pembelajaran Daring SMKN 39 Jakarta
}

\author{
Rizky Wahyu Maulana Salim ${ }^{1}$, Samsul Ma'arif ${ }^{2}$ \\ ${ }^{1,2}$ Pendidikan Matematika, Fakultas Keguruan dan Ilmu Pendidikan, Universitas Muhammadiyah Prof. Dr. Hamka \\ Jl. Tanah Merdeka No. 20 Jakarta Timur, Indonesia \\ rizkywahyums@gmail.com
}

\begin{abstract}
This investigate's reason to portray the sociomathematical norms in understudies that analyzez when learning mathematics online. The subjects of this consider were understudies of SMKN 39 Jakarta. This research method uses a qualitative descriptive method. This study uses the distribution of questionnaires through Google Forms and interviews through Zoom Meetings. Based on the research results, there are 3 students who have high criteria in sociomathematical norms, there are 25 students who have moderate or standard criteria, and there are 2 students who have low criteria. The results of the study concluded that the quality of interactions formed in online learning also decreased, where students almost did not carry out online discussions and presentations. However, we can see that student with high sociomathematical norm criteria are more confident in drawing conclusions. So, the sociomathematical norms are closely related to the relationship between individuals, mathematics and society which emphasizes that students' understanding, and beliefs can be generated or raised during the process of discussion interaction in learning, but because the interactions that occur have decreased in essence, the understanding and beliefs of students also increase. decrease. In addition, the sociomathematical norms possessed by students greatly affect the high and low understanding of the results obtained when learning mathematics takes place.
\end{abstract}

Keywords: Mathematics Online Learning, Sociomathematics, Sociomathematical Norms

\begin{abstract}
Abstrak
Penelitian ini memiliki tujuan untuk menganalisis norma sosiomatematik terhadap peserta didik yang berlangsung ketika pembelajaran daring matematika. Subjek dari penelitian ini adalah peserta didik SMKN 39 Jakarta. Metode penelitian ini menggunakan metode deskriptif kualitatif. Penelitian ini menggunakan penyebaran angket melalui Google Form dan Wawancara melalui Zoom Meeting. Berdasarkan hasil penelitian, terdapat 3 peserta didik yang berkreteria tinggi dalam norma sosiomatematik, terdapat 25 peserta didik yang berkreteria sedang atau standart, dan terdapat 2 peserta didik yang berkreteria rendah. Hasil penelitian menyimpulkan bahwa kualitas interaksi yang terbentuk dalam pembelajaran daring juga mengalami penurunan, dimana peserta didik hampir tidak melaksanakan diskusi secara daring dan presentasi. Namun dapat kita lihat bahwa peserta didik yang kreteria norma sosiomatematiknya tinggi lebih percaya diri untuk menarik kesimpulan. Maka norma sosiomatematik sangat berkenaan dengan hubungan antar individu, matematika dan masyarakat yang menekankan, bahwa pemahaman dan keyakinan peserta didik dapat ditimbulkan atai dimunculkan saat proses interaksi diskusi dalam pembelajaran, namun karena interaksi yang terjadi mengalami penurunan dalam esensi, maka pemahaman dan keyakinan peserta didik juga mengalami penurunan. Selain itu norma sosiomatematik yang dimiliki peserta didik sangat berpengaruh terhadap tingginya maupun rendahnya hasil pemahaman yang di peroleh pada saat pembelajaran matematika berlangsung.
\end{abstract}

Kata kunci: Pembelajaran Daring Matematika, Sosiomatematik, Norma Sosiomatematik

Copyright (c) 2021 Rizky Wahyu Maulana Salim, Samsul Ma'arif

$\triangle$ Corresponding author: Rizky Wahyu Maulana Salim

Email Address: rizkywahyums@ gmail.com (Jl. Tanah Merdeka No. 20 Jakarta Timur, Indonesia)

Received 14 July 2021, Accepted 09 October 2021, Published 25 October 2021

\section{PENDAHULUAN}

Perlu kita ketahui bahwa matematika bukan hanya mengasah kemampuan individual saja tapi dapat meningkatkan kemampuan sosial seperti yang telah di kemukakan oleh Bowers, Cobb, \& McClain (1999) seiring perkembangan waktu matematika hanya dijadikan momok peserta didik sebagai tolak ukur kecerdasan akademik. Sedangkan matematika merupakan sarana berpikir logis, kritis dan kreatif, 
sehingga tidak dapat dipisahkan dari kehidupan manusia. Sejauh penerapan matematika dalam kehidupan, matematika merupakan salah satu jenis aktivitas manusia. Matematika memiliki nilai penting dan dapat membantu peserta didik menghadapi berbagai tantangan hidup dalam berbagai permasalahan yang dihadapinya. Untuk menghadapi berbagai masalah dalam kehidupan, peserta didik memerlukan berbagai alat untuk beradaptasi dengan lingkungan sekolah, masyarakat dan lingkungan jaringan. Jika alat yang berbeda ini dapat digunakan sebagai alat komunikasi dalam acara di semua lingkungan ini, maka alat tersebut akan dianggap berguna.

Interaksi sosial merupakan salah satu masalah utama dari pemahaman sosial konstruktivis. Pemahaman sosial konstruktivisme meyakini bahwa perkembangan kognitif individu merupakan hasil komunikasi internal antar kelompok sosial yang tidak dapat dipisahkan dari kehidupan sehari-hari. Proses belajar yang dilakukan oleh individu tidak hanya dilakukan secara mandiri, tetapi juga dilakukan oleh individu yang juga merupakan bentuk sosial (Widodo \& Purnami, 2018). Dalam pembelajaran sangat erat kaitannya dengan kehidupan sehari-hari. Salah satu tujuan pendidikan dalam pembelajaran sehari-hari juga dibahas dalam UU No. 20 Sistem Pendidikan Nasional Tahun 2003 tentang Pendidikan adalah mewujudkan suasana belajar dan proses pembelajaran secara sadar dan sistematis, agar peserta didik dapat aktif mengembangkan potensi dirinya, sehingga memiliki kekuatan spiritual keagamaan, pengendalian diri, kepribadian, kecerdasan., akhlak mulia, dan apa yang dibutuhkan siswa, keterampilan, dirinya, masyarakat, bangsa dan negara. (Güven \& Dede, 2017)

Menurut Cobb \& Yackel mereka memperluas studi mereka dari ruang kelas umum menjadi normatif argumen matematika tentang kegiatan peserta didik, norma dibedakan menjadi sosial dan sosiomatis. Norma sosial mengekspresikan aspek interaksi sosial kelas yang menjadi normatif (Yackel, Rasmussen, \& King, 2000). Norma-norma tersebut merupakan norma umum yang dapat diberlakukan di bidang apa saja (Cobb \& Yackel, 1996b). Misalnya, menjelaskan dan membenarkan solusi, mengidentifikasi dan menyatakan persetujuan, mencoba memahami penjelasan orang lain, mengekspresikan ketidak sepakatan tentang ide, dan sebagainya adalah norma sosial untuk diskusi dimana seluruh kelas berpartisipasi (Rizkianto, 2013). Terdapat dua macam norma yang ditemui dalam pembelajaran yaitu, norma sosial (Social Norms) dan norma sosiomatematik (Sociomathematical Norms). Yackel dan Cobb (1996) mengemukakan terdapat perbedaan antara norma sosial dan norma soiomatematik. Norma sosial adalah pola umum interaksi sosial yang tidak ada hubungannya dengan topik pembelajaran atau materi pembelajaran. Contoh sederhananya adalah bagaimana menyampaikan pendapat dan menghargai pendapat orang lain. Standar matematika sosial secara khusus melibatkan pemikiran matematis, yaitu bagaimana peserta didik berinteraksi dan bernegosiasi untuk memahami konsep matematika. Yackel dan Cobb (1996) mengemukakan bahwa "pemahaman dan kesadara pelajar tentang bagaimana mengkomunikasikan pengambilan keputusan dan gaya berpikir" merupakan contoh dari norma sosial dan "pemahaman argumentasi seperti apa yang dapat diterima secara matematis" merpukan contoh dari norma sosiomatematik. Maka dari itu terbentuklah norma-norma sosial yang berkaitan dengan sopan santun atau tata krama dalam berkomunikasi. 
Analisis Sociomathematical Norms Peserta Didik dalam Pembelajaran Daring SMKN 39 Jakarta, Rizky Wahyu Maulana

Tabel 1. Perbedaan Norma Sosial dan Norma Sosiomatematik

\begin{tabular}{|l|l|}
\hline \multicolumn{1}{|c|}{ Norma Sosial } & \multicolumn{1}{c|}{ Norma Sosiomatematik } \\
\hline $\begin{array}{l}\text { Peserta didik saling bertanya tentang ide yang } \\
\text { mereka pikirkan }\end{array}$ & $\begin{array}{l}\text { Peserta didik mengajukan pertanyaan kepada } \\
\text { diri sendiri yang menekankan kepada penalaran, } \\
\text { argumentasi, dan pemahaman matematis }\end{array}$ \\
\hline Peserta didik menjelaskan ide-ide mereka & $\begin{array}{l}\text { Peserta didik menjelaskan pembenaran mereka } \\
\text { dengan argumen matematis }\end{array}$ \\
\hline $\begin{array}{l}\text { Peserta didik memecahkan masalah dengan } \\
\text { bekerja bersama }\end{array}$ & $\begin{array}{l}\text { Peserta didik mencapai kesepakatan melalui } \\
\text { penalaran dan pembuktian matematis }\end{array}$ \\
\hline $\begin{array}{l}\text { Peserta didik menggunakan metode yang } \\
\text { berbeda untuk memecahkan masalah }\end{array}$ & $\begin{array}{l}\text { Peserta didik menyamakan strategi untuk } \\
\text { mendapatkan persamaan serta kelainan yang } \\
\text { berguna secara matematis }\end{array}$ \\
\hline $\begin{array}{l}\text { Peserta didik menyadari jika kesalahan } \\
\text { merupakan bagian dari pembelajaran }\end{array}$ & $\begin{array}{l}\text { Peserta didik memanfaatkan kesalahan sebagai } \\
\text { peluang untuk secara konseptual memikirkan } \\
\text { kembali ide- ide matematika serta mengecek } \\
\text { kontradiksi. Kesalahan meberikan pembelajaran } \\
\text { matematika yang baru }\end{array}$ \\
\hline
\end{tabular}

Source (Kadir, 2008)

Berkaitan dengan terdapatnya wabah Covid- 19 yang tengah dialami bersama, pemerintah kemudian menghasilkan himbauan untuk melaksanakan aktivitas pembelajaran dari rumah. Metode pembelajaran di seluruh dunia yang awalnya melalui tatap muka di kelas berubah menjadi menggunakan daring sebagai alat untuk berinteraksi keluar rumah saat semua orang berada di dalam rumah, upaya ini bertujuan agar tidak terjadi perluasan Covid-19 ini. Namun perbedaan interaksi saat ini tidak menurunkan kualitas peserta didik untuk mendapatkan tujuan pembelajaran dari matematika ini (Utami \& Cahyono, 2020). Menurut Tuncay terdapat jenis pembelajaran lain yang dapat digunakan oleh tenaga pengajar sebagai fasilitas penyampaian ilmu pengetahuan, yakni pembelajaran daring dan pembelajaran campuran (kombinasi berasal dari dua metode pembelajaran yakni tatap muka dan pembelajaran daring). Pembelajaran full online dianggap tidak cukup bisa mengakomodasi semua keperluan pembelajaran, maka pembelajaran campuran atau blended learning menjadi salah satu alternative yang memadai untuk diminati oleh tenaga pengajar. (Zhafira et al., 2020)

Adapun masalah ketika peserta didik belajar matematika secara online (E-Learning) di rumah, mereka sering mengalami kesulitan mengenali terhadap konsep dan kemampuan diri yang mereka miliki, dikarenakan: 1) peserta didik tidak dapat mengembangkan inisiatif belajarnya sendiri, terkesan menunggu instruksi atau pekerjaan rumah dari guru selama proses pembelajaran; 2) peserta didik belum terbiasa belajar melaksanakan kebutuhan pembelajaran online di rumah, peserta didik mempelajari materi matematika berdasarkan apa yang diberikan guru, bukan apa yang mereka butuhkan; 3) tujuan pembelajaran online atau tugas peserta didik di kelas matematika masih sebatas memperoleh nilai yang memuaskan, bukan ketermapilan yang harus ditingkatkan; 4) beberapa peserta didik masih belum dapat memantau, mengatur dan mengontrol pembelajaran online di rumah, dan mereka masih belajar sesuai permintaan; 5) peserta didik masih banyak yanh menyerah dalam menghadapi penyelasaian tugas - 
tugas matematika E-Learning ketika terdapat kesulitan dan keselahan, mereka juga jarang mengevaluasi proses dari hasil pembelajaran mereka.(Fitriana, 2018)

Salah satu bidang yang mempunyai efek besar terhadap pembangunan teknologi ini didalam bidang pendidikan, pada dasarnya pendidikan adalah sistem komunikasi dan informasi berasal dari pendidik ke peserta didik, meliputi: Informasi pendidikan, berdasarkan unsur pendidik informasi, media sebagai fasilitas pengungkapan ide, gagasan, dan materi pendidikan, dan peserta didik itu sendiri. Lebih dari satu unsur paparan tempat teknologi informasi, yang berujung terhadap lahirnya gagasan mengenai E-Learning. Untuk mencapai tujuan pembelajaran matematika dikelas daring, ada beberapa karakteristik peserta didik yang mempengaruhi keragaman suasana didalam kelas daring tersebut dapat berupa suatu hal yang berhasil maupun gagal dalam mencapai tujuan pembelajaran matematika.(Utari, 2017) Maka dari itu hal yang sangat mendukung karakteristik peserta didik untuk mencapai keberhasilan adalah interaksi secara daring. Dengan melalui interaksi yang sudah dilaksanakan ini dapat memunculkan sebuah norma sosiomatematik. Berdasarkan dari uraian dan serangkaian penelitian yang sudah dilakukan, maka dapat disimpulkan penelitian ingin bertujuan untuk mengetahui sejauh mana pentingnya dan kegunaan sociomathematical norms dalam menunjang keberhasilan pembelajaran daring matematika SMKN 39 Jakarta.

\section{METODE}

Alur penelitian ini menggunakan metode deskriptif kualitatif yang bertujuan untuk mendeskripsikan bagaimana berjalannya norma sosiomatematik peserta didik dalam pembelajaran daring matematika. Tempat penelitian dilaksanakan di SMKN 39 Jakarta, jalan Cempaka Putih Tengah VI No.2, Cempaka Putih 10510 Jakarta Pusat, Daerah Khusus Ibukota Jakarta, Indonesia. Pengambilan data dilaksanakan pada bulan Juni - Juli tahun 2021 dengan menerapkan pembelajaran daring melalui Google classroom, whatsapp group, google form, dan zoom meeting untuk bertujuan agar meminimalisir dan mencegah penyebaran covid 19. Terdapat beberapa tahapan yang dilaksanakan dalam penelitian ini dimulai dari persiapan pengambilan data, pengelolahan data, sampai akhirnya mendapatkan hasil akhir dari penelitian ini. Bagan alur dari penelitian yang sudah dilaksanakan dapat dilihat pada Gambar 1.(Fatmawati, 2009).

Karena penelitian ini adalah kualitatif menurut Moleong, mengatakan bahwa sumber data yang didapatkan terdiri dari 2 sumber data yaitu, Sisanya merupakan data tambahan, seperti dokumen atau sumber data tertulis, foto, dan statistik. Perkataan dan perbuatan yang diamati atau orang yang diwawancarai menjadi sumber data utama. Sumber data utama adalah catatan tertulis atau video maupun audio, rekaman suara, dan fotografi. Sedangkan sumber data lainnya dari sumber tertulis dapat dirinci menjadi buku dan jurnal ilmiah, berasal dari arsip, dokumen pribadi, dan dokumen pemerintah.(Rijali, 2019). 
Analisis Sociomathematical Norms Peserta Didik dalam Pembelajaran Daring SMKN 39 Jakarta, Rizky Wahyu Maulana

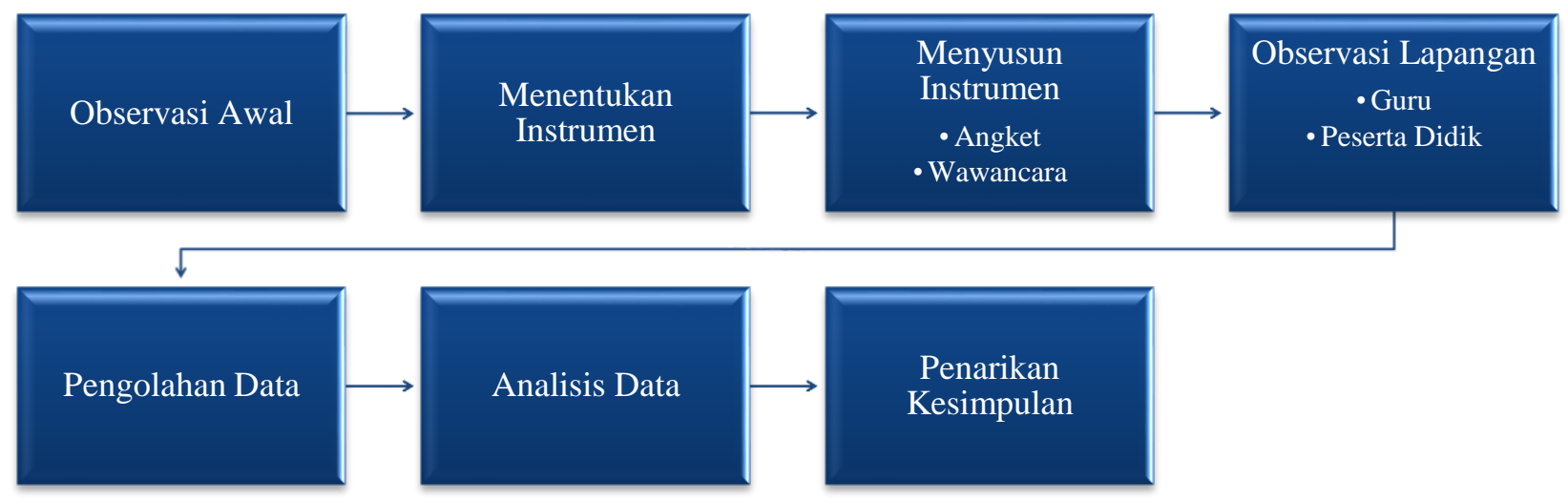

Gambar 1 Alur Penelitian

Dalam penentuan subjek penelitian dilakukan dengan penyebaran angket melalui Whatsapp Group berbentuk Google Form yang telah dibuat oleh peneliti dan sudah disahkan oleh dosen pembimbing. Subjek yang diteliti adalah 1 kelas yang terdiri dari 30 peserta didik dan dipilih menjadi 4 peserta dengan cara pengelompokan. Sehingga mendapatkan 2 peserta didik dengan kriteria tinggi dan 2 peserta didik dengan kriteria rendah berdasarkan pengisian angket yang sudah dilakukan. Setelah mendapatkan 4 peserta didik, peneliti memberikan 4 soal dengan waktu pengerjaan 4x10 menit untuk mengetahui sejauh mana peserta didik dapat memahami materi yang sudah di berikan oleh guru, sekaligus mensikronisasi kriteria peserta didik dengan pemahaman materi yang telah didapatkan.

Tes pemahaman dari angket norma sosiomatematik yang telah dilakukan yaitu tes pilihan ganda terdiri dari 30 soal. Soal - soal ini mempunyai beberapa indikator yang terdiri antara lain: (1) Menghilangi Norma Keambiguaan (Non-ambiguity Norm), (2) Pemahaman Norma Oraang Ketiga (Third Person Norm Comprehension), (3) Pembenaran Norma Matematika (Justification Mathematical Norm), (4) Perbedaan Norma Matematika (Differentiation Mathematical Norm), (5) Efektivitas Matematika (Mathematics Effektivenes), (6) Wawasan Matematika (Mathematical Insight).

Wawancara dilakukan menggunakan metode tidak terstruktur mengikuti kutipan dari Tohirin yang berpendapat bahwa dalam studi kualitatif terhadap wawancara mendalam cenderung dilakukan secara tidak terstruktur. Data dikumpulkan selama wawancara, biasanya data lisan dikumpulkan melalui wawancara atau tanya jawab. Peneliti juga melakukan dokumentasi yang digunakan sebagai membantu pengumpulan data berbentuk foto bagian jawaban angket, bagian hasil jawaban soal, serta vidio Zoom Meeting, dan juga menulis cuplikan perbincangan dalam vidio tersebut.(Anisa et al., 2019)

Metode yang peneliti gunakan untuk menganalisis data adalah teknik pemodelan dari Miles dan Hubermann. Miles dan Huberman menyarankan bahwa kegiatan analisis data kualitatif harus dilakukan secara interaktif dan berlanjut sampai selesai untuk menjaga saturasi data. Adapun kegiatan analisis data yaitu pengolahan data (Data Reduction), data display dan ekstraksi/validasi penalaran (Verification). 


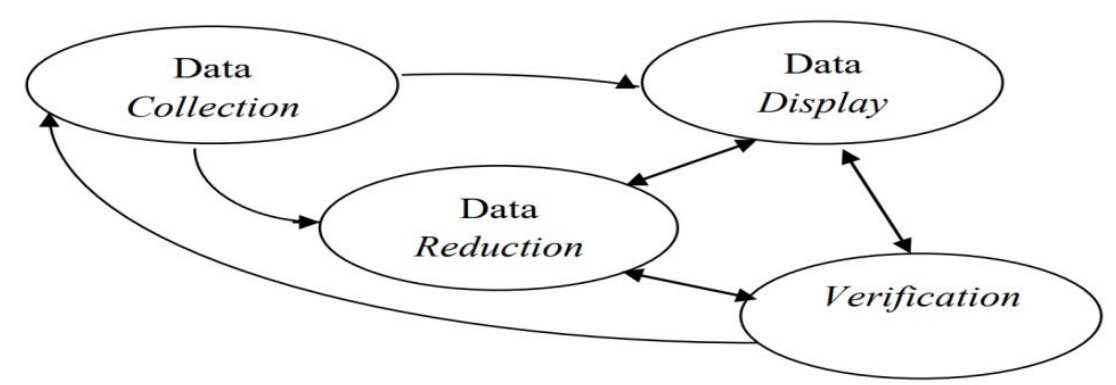

Gambar 2 Analisis Data (A.B. Spierings, M. Voegtlin, T. Bauer, 2015)

Setelah itu data dilakukan triangulasi supaya mendapatkan keabsahan pada data yang diteliti. Penelitian ini menggunakan triangulasi teknik, yaitu membandingkan hasil wawancara dan observasi pada sumber yang sama. Triangulasi teknik digunakan untuk menguji kredibilitas data dengan cara mengecek data kepada sumber yang sama dengan teknik yang berbeda.

\section{HASIL DAN DISKUSI}

\section{Hasil}

Sebelum melakukan penelitian, peneliti melakukan pengujian uji validitas angket terlebih dahulu dilakukan melalui Google Form dan diujikan kepada 30 peserta didik kelas XI. Upaya tersebut dikhusukan untuk mengetahui kelayakan pada angket tersebut. Kisi - kisi dari angket ini terdiri dari beberapa indikator. Indikator tersebut diambil dari peneliti sebelumya yaitu penelitian yang dilakukan oleh Yackel \& Cobb (1996) dan Tatsis (2008) serta beberapa tambahan indikator yang dikemukakan oleh Kang \& Kim (2015). Peneliti menggabungkan indikator-indikator tersebut agar hasil penelitian dapat lebih akurat dan tepat. Angket norma sosiomatematik ini di uji validitas dan reliabilitas kepada kelas XI EI 1 terlebih dahulu dan mendapatkan hasil seperti tabel berikut ini. (Muhaimin \& Astuti, 2018)

Tabel 2. Uji Validasi

\begin{tabular}{|c|l|c|c|c|}
\hline No. & \multicolumn{1}{|c|}{ Indikator } & $\begin{array}{c}\text { Jumlah } \\
\text { Pernyataa } \\
\text { n }\end{array}$ & $\begin{array}{c}\text { Pernyataan } \\
\text { Tidak Valid }\end{array}$ & $\begin{array}{c}\text { Pernyataan } \\
\text { Valid }\end{array}$ \\
\hline 1 & $\begin{array}{l}\text { Menghilangi Norma Keambiguaan } \\
\text { (Non-ambiguity Norm) }\end{array}$ & 5 & 2 & 3 \\
\hline 2 & $\begin{array}{l}\text { Pemahaman Norma Orang Ketiga } \\
\text { (Third Person Norm Comperhension) }\end{array}$ & 5 & 1 & 4 \\
\hline 3 & $\begin{array}{l}\text { Pembenaran Norma Matematika } \\
\text { (Justification Mathematical Norm) }\end{array}$ & 5 & 2 & 3 \\
\hline 4 & $\begin{array}{l}\text { Perbedaan Norma Matematika } \\
\text { (Differentiation Mathematical Norm) }\end{array}$ & 5 & 5 & 5 \\
\hline 5 & $\begin{array}{l}\text { Efektivitas Matematika } \\
\text { (Mathematics Effektivenes) }\end{array}$ & 5 & & 5 \\
\hline 6 & $\begin{array}{l}\text { Wawasan Matematika } \\
\text { (Mathematical Insight) }\end{array}$ & 5 & & \\
\hline
\end{tabular}


Analisis Sociomathematical Norms Peserta Didik dalam Pembelajaran Daring SMKN 39 Jakarta, Rizky Wahyu Maulana Salim $^{1}$, Samsul Ma'arif

Dengan ini sangat terlihat jelas bahwa kisi - kisi yang digunakan sebagai pedoman penelitian untuk membuat angket norma sosiomatematik ini. Setelah di uji validitas, maka terdapat 5 pernyataan yang tidak valid dari 30 pernyataan yang telah dibuat oleh peneliti. Menurut Sugiyono(168: 2016) "Valid artinya alat ukur yang digunakan untuk meperoleh data (pengukuran) itu valid. Valid berarti alat yang dapat mengukur hal yang diukur.” Dengan menghitung nilai yang dinyatakan dari setiap item dan alat ukur korelasi antara nilai total untuk memeriksa validitas alat ukur. Metode yang digunakan adalah Product Moment.

Setelah mendepatkan validitas dari pernyataan di atas maka pengambilan data dilaksanakan dengan cara penyeberan angket dikurangi pernyataan yang tidak valid melalui via Whatssapp Group berbentuk Google Form, kemudian peneliti memberikan skor dari setiap peserta didik yang menjawab soal angket tersebut sehigga terkelompokkan peserta didik yang berkreteria tinggi dan berkreteria rendah masing - masing terdapat 2 peserta didik. Kreteria ini didapatkan dari skor tertinggi dikelas dan skor terendah dikelas, agar dapat mempermudah penggambaran peneliti sudah membuat tabel yang menggambarkan skor tertinggi dan terendah dikelas seperti pada Tabel 2.

Tabel 3. Transkip Skor Nilai

\begin{tabular}{|c|c|c|c|c|}
\hline No & Nama & Keterangan & Total Skor & Deskripsi \\
\hline 1 & Do & L & 72 & Sedang \\
\hline 2 & M Z & L & 63 & Sedang \\
\hline 3 & A I H L & L & 65 & Sedang \\
\hline 4 & E R K & L & 71 & Sedang \\
\hline 5 & M A & L & 56 & Rendah \\
\hline 6 & R S P & P & 67 & Sedang \\
\hline 7 & M R & L & 71 & Sedang \\
\hline 8 & A T & L & 79 & Tinggi \\
\hline 9 & R K & L & 65 & Sedang \\
\hline 10 & A W & L & 68 & Sedang \\
\hline 11 & F G & L & 64 & Sedang \\
\hline 12 & D A Z & L & 68 & Sedang \\
\hline 13 & M A & P & 72 & Sedang \\
\hline 14 & MF R & L & 77 & Tinggi \\
\hline 15 & R B A & L & 66 & Sedang \\
\hline 16 & H S & L & 73 & Sedang \\
\hline 17 & M P & P & 71 & Sedang \\
\hline 18 & R F & L & 66 & Sedang \\
\hline 19 & A G & L & 71 & Sedang \\
\hline 20 & M L H & L & 68 & Sedang \\
\hline 21 & F D R & L & 75 & Tinggi \\
\hline 22 & A C & L & 71 & Sedang \\
\hline 23 & I A & L & 58 & Rendah \\
\hline 24 & R J P & L & 67 & Sedang \\
\hline & & & & \\
\hline
\end{tabular}




\begin{tabular}{|l|c|l|l|l|}
\hline 25 & D S & L & 63 & Sedang \\
\hline 26 & F G & L & 64 & Sedang \\
\hline 27 & A S & L & 68 & Sedang \\
\hline 28 & C A H & L & 73 & Sedang \\
\hline 29 & I N & L & 65 & Sedang \\
\hline 30 & Mah & P & 67 & Sedang \\
\hline
\end{tabular}

Berdasarkan hasil tabel yang di atas, maka peneliti mengambil 2 subjek dengan skor tertinggi dan 2 subjek dengan skor terendah. Data hasil angket norma sosiomatematik yang diperoleh menunjukkan 4 peserta didik memiliki kategori sangat baik dan kategori kurang terhadap norma sosiomatematik. Kategori pengelompokkan terdir dari kriteria tertinggi > 75, kriteria sedang $60-75$, kriteria rendah < 60 rendah. Untuk mempermudah peneliti memproses analisis data, maka peneliti membuat kode untuk setiap subjek penelitian sebagai berikut.

Tabel 4. Subjek Penelitian

\begin{tabular}{|c|c|c|c|}
\hline No & Inisial & Kode & Deskripsi Angket \\
\hline 1 & AT & S1 & Tinggi \\
\hline 2 & MFR & S2 & Tinggi \\
\hline 3 & IA & S3 & Rendah \\
\hline 4 & MA & S4 & Rendah \\
\hline
\end{tabular}

Berdasarkan tabel 3 dapat di simpulkan terdapat 2 peserta didik yang diambil berdasarkan kriteria tinggi berinisial AT (S1) serta MFR (S2) dan 2 peserta didik lainnya berkreteria rendah berinisial IA (S3) serta MA (S4). Setelah mendapatkan masing - masing 2 peserta didik untuk setiap kriteria peneliti memberikan soal yang sudah mereka pelajari dan hasilnya dilampirkan seperti dibawah ini. Terdapat 30 soal pilihan ganda untuk mengetes pemahaman peserta didik, peneliti memilih beberapa soal yang akan mereka kerjakan disertakan cara pengerjaan mereka dan soal - soal tersebut berasal dari soal uas yang mereka telah kerjakan.

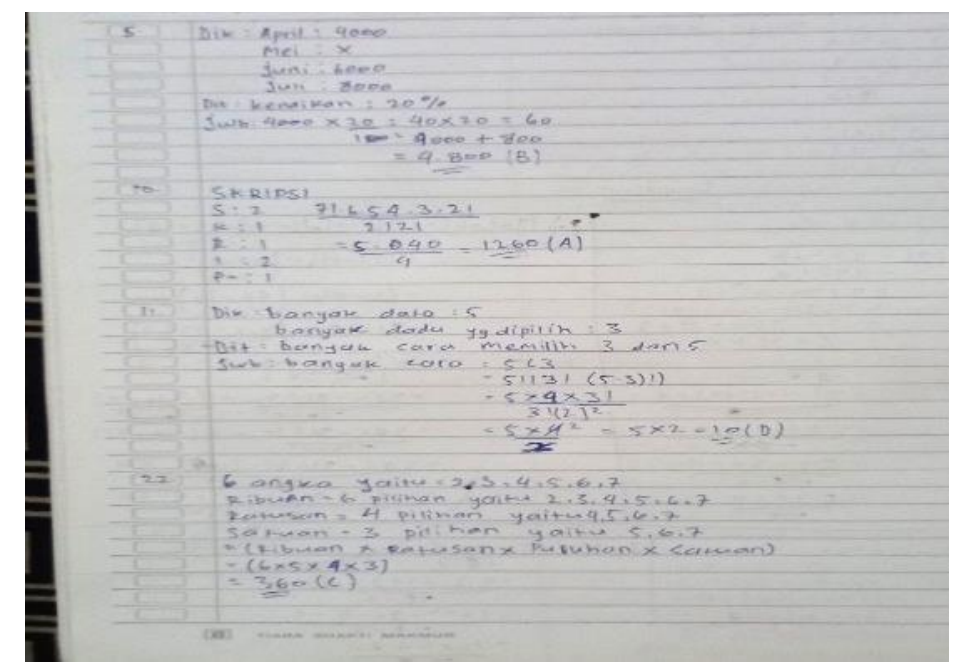

Gambar 3. Hasil Jawaban AT 
Analisis Sociomathematical Norms Peserta Didik dalam Pembelajaran Daring SMKN 39 Jakarta, Rizky Wahyu Maulana Salim ${ }^{1}$, Samsul Ma'arif

Berdasarkan jawaban dari S1 (AT) terlihat jelas bahwa pengerjaan dan cara penyampain pendapat AT lebih tersetruktur dimana dimulai dari diketahui, ditanya hingga jawaban dari soal tersebut.

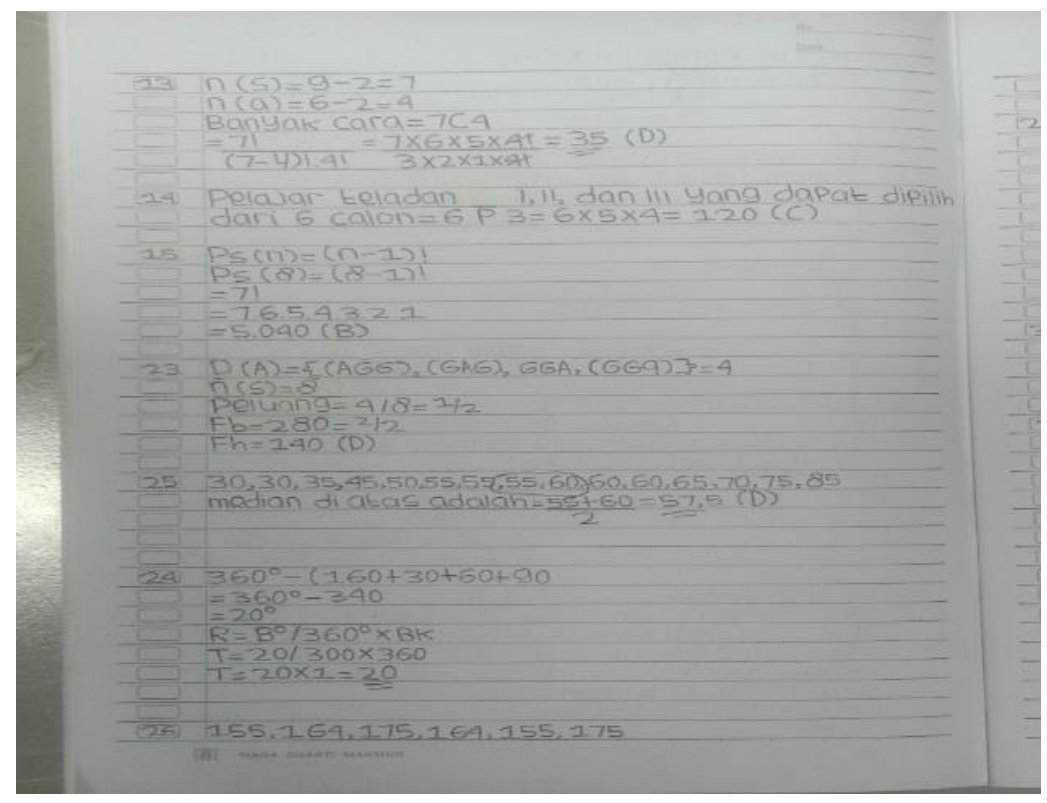

Gambar 4. Hasil Jawaban MFR

Berdasarkan jawaban dari S2 (MFR) juga masih terlihat dia mampu memberikan jawaban yang di awali dengan diketahui dari soal yang ada, hingga cara dari jawaban yang dia dapatkan. Serta masih terlihat terstruktur untuk pendekatan - pendekatan pemahaman materinya.

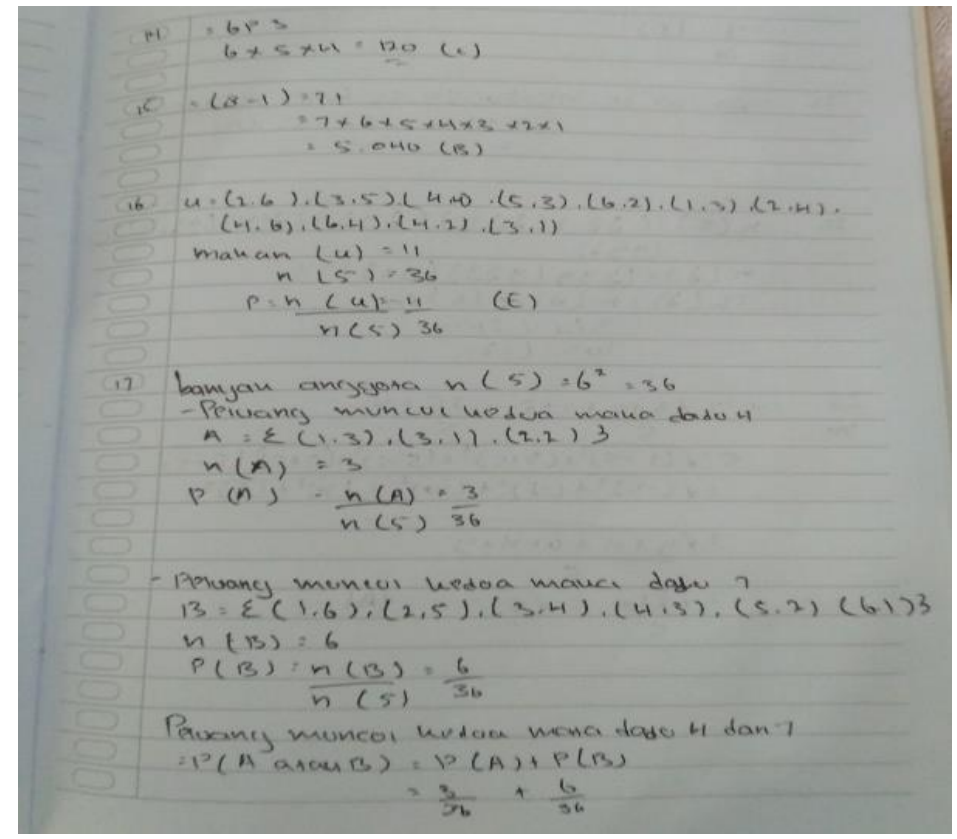

Gambar 5. Hasil Jawaban IA

Dari jawaban di atas dapat terlihat bahwa S3 (IA) terkesan buru - buru dalam pengerjaan soal tanpa pencantuman data - data yang didapkan dari pemahaman soal yang diberikan. 


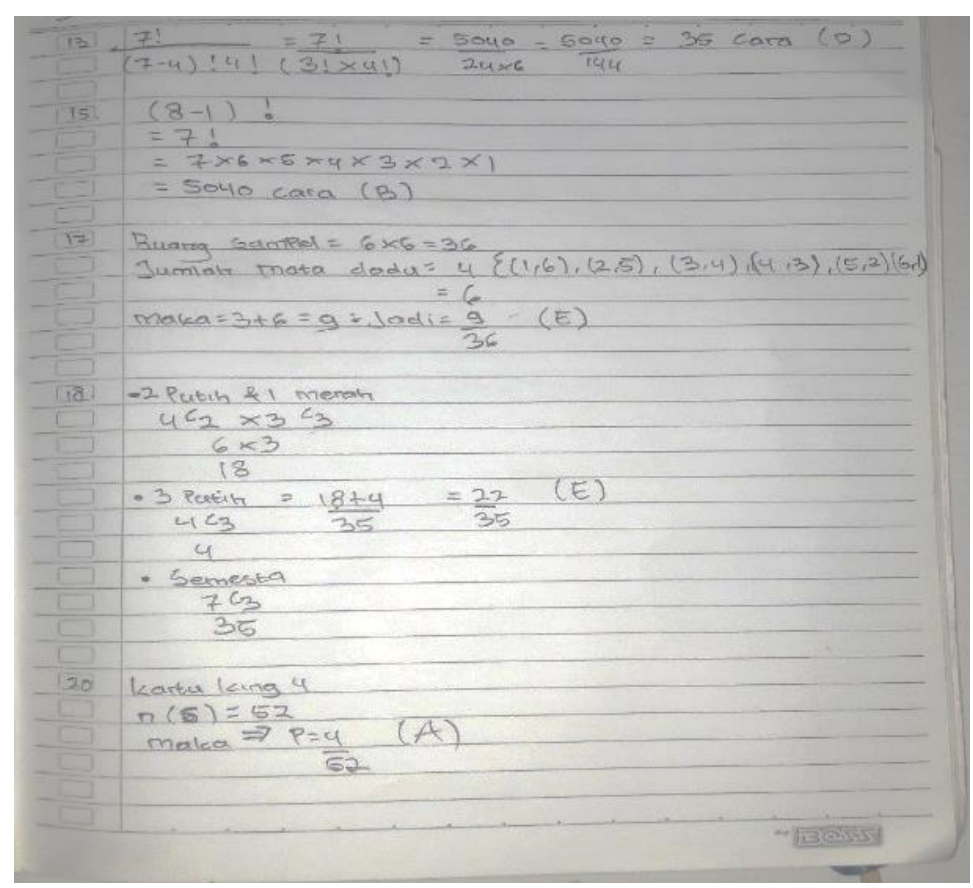

Gambar 6 Hasil Jawaban MA

Jawaban yang dituliskan dari S4 (MA) terlihat tidak jauh berbeda dari S3 karena tidak adanya penjelasan pemahaman mereka dari soal sepertia diketahui hingga cara dari jawaban tersebut. Hal ini menunjukan bahwa dari ke empat peserta yang akan diteliti memiliki latar belakang yang berbeda dari pengerjaan mereka. Maka dari itu peneliti ingin mengetahui dari ke empat peserta didik tentang pemahaman mereka pentingnya norma sosiomatematik dengan hasil pembelajaran.

Menurut Table 3 di atas peneliti ingin menyampaikan beberapa pertanyaan berupaya untuk mengetahui lebih mendalam tentang norma sosiomatematik mereka. Berikut ini adalah cuplikan wawancara dari indikator - indikator penelitan yang telah dilaksanakan. Serta mengskronisasi dengan pemahaman dan tingkah laku dalam penerapan norma sosiomatematik dalam pembelajaran daring matematika.

\section{Cuplikan Wawancara S1 inisial AT}

$P$ : Apakah anda dapat memahami materi yang disampaikan oleh guru melalui daring?

$S$ : Kalau penjelasan lebih enak tatap langsung kalau melalui daring agak kurang dipahami

$P$ : Ketika berdiskusi dalam kelas daring, apakah Anda menerima argumen teman lain yang berbeda?

$S$ : Terima karena pendapat lebih banyak lebih bagus dan harus dicerna lagi

$P$ : Bagaimana perasaan Anda ketika teman lain tidak menyukai argumen Anda?

$S$ : Agak sedikit kecewa jika tidak diterima argumen saya namun mungkin sebagai pemahaman baru buat saya

$P$ : Apakah Anda dapat menarik kesimpulan dari pembelajaran daring yang telah diberikan?

$S$ : Iya saya dapat menyimpulkannya 
Analisis Sociomathematical Norms Peserta Didik dalam Pembelajaran Daring SMKN 39 Jakarta, Rizky Wahyu Maulana Salim $^{1}$, Samsul Ma'arif

Terdapat 7 pertanyaan tentang mendukung penelitian ini namun dari jawaban S1 yang dapat sangat jelas dalam pemahaman tentang norma sosiomatematik hanya sedikit maka peneliti membuang pernyataan yang kurang efektif dan mempersingkatnya dengan 3 pertanyaan tentang Third Person Norm Comperhension, 1 pernyaan tentang Differentiation Mathematical Norm, 2 pertanyaan tentang Mthematical Insight, serta 1 pertanyaan tentang Mathematics Effektivenes.

Berdasarkan hasil wawancara di atas dapat diketahui bahwa S1 dapat mengikuti serta beradaptasi dengan pembelajaran daring yang dilaksanakan disemua kurikulum saat ini ,dapat dilihat bahwa S1 mampu memahami materi dan menarik kemsimpulan yang disampaikan oleh guru walaupun masih terasa agak sulit memahami materi dibandingkan langsung bertatap muka (offline) dan S1 dapat menerima argumennya ditolak oleh teman lainnya walaupun sebenarnya dia sedikit merasa kecewa, serta S1 masih percaya diri untuk bisa menarik kesimpulan di setiap pembalajaran daring.

Dari hasil data wawancara yang telah diperoleh, maka dapat disimpulkan bahwa S1 termasuk kriteria tinggi dan memiliki norma sosiomatematik yang baik ketika pembelajaran daring.

\section{Cuplikan Wawancara untuk S2 inisial MFR}

$P$ : Apakah Anda dapat memahami materi yang disampaikan oleh guru melalui daring?

$S$ : Kurang lebih ngerti tatap langsung dari pada hanya lewat tes dan tugas

$P$ : Ketika berdiskusi dalam kelas daring, apakah Anda menerima argumen teman lain yang berbeda?

$S$ : Ketika berbeda rumus saya dapat menerimanya

$P$ : Bagaimana perasaan Anda ketika teman lain tidak menyukai argumen Anda?

$S$ : Tidak apa - apa karena mungkin pendapat orang lain lebih baik dari saya

$P$ : Apakah Anda dapat menarik kesimpulan dari pembelajaran daring yang telah diberikan?

$S$ : Tidak setiap juga sih karena ada juga yang tidak mengerti namun saya dapat menyimpulkannya

Terdapat 9 pertanyaan tentang mendukung penelitian ini namun dari jawaban S2 yang dapat sangat jelas dalam pemahaman tentang norma sosiomatematik hanya sedikit maka peneliti membuang pernyataan yang kurang efektif dan mempersingkatnya dengan 1 pertanyaan tentang Non-Ambiguity Norm, 2 pertanyaan tentang Third Person Norm Comperhension, 2 pertanyaan tentang Differentiation Mathematical Norm, 2 pertanyaan tentang Mathematical Insight, 2 pertanyaan tentang Justification Mathematical Norm, serta 1 pertanyaan tentang Mathematics Effektivenes.

Berdasarkan hasil wawancara di atas dapat diketahui bahwa S2 dapat mengikuti serta beradaptasi dengan pembelajaran daring yang dilaksanakan disemua kurikulum saat ini ,dapat dilihat bahwa S2 mampu memahami materi yang disampaikan oleh guru walaupun masih terasa agak sulit memahami materi dibandingkan langsung bertatap muka (offline), S2 juga dapat menerima argumen temannya yang lain berbeda dari dirinya, selain itu S2 dapat membayangkan jika argumennya ditolak oleh teman lainnya maka dia menghargai pendapat orang tersebut karena mungkin argumen orang itu lebih baik dari dia, 
serta S2 masih percaya diri untuk bisa menarik kesimpulan walaupun tidak semua materi saat pembalajaran daring bisa dia tarik kesimpulan.

Dari hasil data wawancara yang telah diperoleh, maka dapat disimpulkan bahwa S2 termasuk kriteria tinggi dan memiliki norma sosiomatematik yang baik ketika pembelajaran daring.

\section{Cuplikan Wawancara untuk S3 inisial IA}

$P$ : Apakah Anda dapat memahami materi yang disampaikan oleh guru melalui daring?

$S$ : Kurang memahami karena melalui daring hanya memberikan soal saja berbeda dari offline

$P$ : Bagaimana perasaan Anda ketika teman lain tidak menyukai argumen Anda?

$S$ : Sampai saat ini saya belum bisa membayangkannya karena saya belum pernah berargumen ketika pembelajaran daring

Terdapat 9 pertanyaan tentang mendukung penelitian ini namun dari jawaban S3 yang dapat sangat jelas dalam pemahaman tentang norma sosiomatematik hanya sedikit maka peneliti membuang pernyataan yang kurang efektif dan mempersingkatnya dengan 2 pertanyaan tentang Non-Ambiguity Norm, 2 pertanyaan tentang Third Person Norm Comperhension, 1 pertanyaan tentang Differentiation Mathematical Norm, 2 pertanyaan tentang Mathematical Insight, 2 pertanyaan tentang Justification Mathematical Norm, serta 1 pertanyaan tentang Mathematics Effektivenes.

Berdasarkan hasil wawancara di atas dapat diketahui bahwa S3 mengalami kesulitan dalam berinteraksi maupun beradaptasi dengan pembelajaran daring yang dilaksanakan disemua kurikulum saat ini, dapat dilihat bahwa S3 kurang memahami tentang materi yang telah disampaikan oleh guru karena sangat berbeda dari pembelajaran offline, selain itu S3 tidak bisa memahami maupun membayangkan tentang argumentasi yang tidak disetujui oleh teman - temannya dengan alasan S3 belum pernah berargumentasi di pembelajaran daring, serta S3 hanya sedikit atau lebih tepatnya ragu untuk bisa menarik kesimpulan di setiap pembalajaran daring yang sudah berlangsung.

Dari hasil data wawancara yang telah diperoleh, maka dapat disimpulkan bahwa S3 termasuk kriteria rendah dan memiliki norma sosiomatematik yang kurang baik ketika pembelajaran daring.

\section{Cuplikan Wawancara S4 inisial MA}

$P$ : Apakah Anda yakin ketika mempresentasikan hasil penyelesaian masalah yang ditemukan dalam pembelajaran daring?

$S$ : Tidak begitu yakin soalnya gugup dan malu juga

$P$ : Apakah Anda selalu bertanya kepada guru ketika tidak memahami masalah yang diberikan?

$S$ : Jarang karena sama guru jadi suka malu

$P$ : Bagaimana Anda menjelaskan penyelesaian soal matematika jika disuruh oleh guru dalam pembelajaran daring? 
Analisis Sociomathematical Norms Peserta Didik dalam Pembelajaran Daring SMKN 39 Jakarta, Rizky Wahyu Maulana Salim $^{1}$, Samsul Ma'arif

S : Saya jelaskan sebisa saya saja mengikuti jawaban yang telah saya kerjakan tapi terkadang tidak tau dan bertanya pada guru juga

Terdapat 6 pertanyaan tentang mendukung penelitian ini namun dari jawaban S4 yang dapat sangat jelas dalam pemahaman tentang norma sosiomatematik hanya sedikit maka peneliti membuang pernyataan yang kurang efektif dan mempersingkatnya dengan 1 pertanyaan tentang Non-Ambiguity Norm, 2 pertanyaan tentang Third Person Norm Comperhension, 1 pertanyaan tentang Differentiation Mathematical Norm, 1 pertanyaan tentang Mthematical Insight, 1 pertanyaan tentang Justification Mathematical Norm, serta 2 pertanyaan tentang Mathematics Effektivenes.

Berdasarkan hasil wawancara di atas, dapat diketahui bahwa S4 kurangnya percaya diri dalam mengikuti pembelajaran daring, dapat dilihat S4 kurang memahami tentang materi dikarenakan dia gugup dan malu, selain itu S4 lebih senang berdiskusi dengan teman - temannya dari pada meminta arahan dari guru, serta S4 hanya mengikuti arahan dari guru dan masih belum memiliki kepercayaan diri kepada hasil jawaban yang dia miliki. Dari hasil data wawancara yang telah diperoleh, maka dapat disimpulkan bahwa S4 termasuk kriteria rendah dan memiliki norma sosiomatematik yang kurang baik ketika pembelajaran daring.

\section{Diskusi}

Sekian banyaknya pemaham peserta didik tentang norma sosiomatematik, maka dapat disimpulkan bahwa norma sosiomatematik merupakan pembelajaran yang berkaitan dengan keyakinan dan pemahaman peserta didik tentang matematika, bagaimana peserta didik dan guru saling menerima argumen atau penjelasan secara matematis. Norma sosiomatematik dapat membantu peserta didik untuk saling mengungkapkan pendapatnya melalui diskusi yang dilakukan secara daring. Hal ini relevan dengan penelitian (Sulfikawati et al., 2016) menunjukkan bahwa analisis norma sosiomatematik sebagian besar subyek penelitian memiliki kategori keyakinan tinggi terhadap aktivitas kolaborasi atau dengan kata lain subyek tersebut memiliki kemampuan komunikasi matematik dan keterampilan sosial yang baik bahkan sangat baik. Menurut (Aslamiah, 2018) mengatakan bahwa norma sosiomatematik berkorelasi positif dengan prestasi belajar matematika peserta didik, atau semakin tingginya norma sosiomatematik maka prestasi belajar matematika peserta didik semakin tinggi.

\section{KESIMPULAN}

Berdasarkan hasil dari penelitian dan pembahan yang telah dilaksana dalam pembelajaran daring matematika. Peserta didik mengalami banyak kesulitan dalam memahami materi yang diberikan bisa disimpulkan dari ke 4 peserta didik yang di wawancarai, semua berpendapat bahwa belajar melalui tatap muka (offline) lebih mudah dipahami, serta sangat membantu peserta didik mendapatkan kepercayaan diri mereka. Kualitas interaksi yang terbentuk dalam pembelajaran daring juga mengalami penurunan, dimana peserta didik hampir tidak melaksanakan diskusi secara daring dan presentasi. Namun dapat kita 
lihat bahwa peserta didik yang kreteria norma sosiomatematiknya tinggi lebih percaya diri untuk menarik kesimpulan.

Maka norma sosiomatematik sangat terkait dengan hubungan antar individu, matematika dan masyarakat yang menekankan bahwa pemahaman dan keyakinan peserta didik dapat ditimbulkan atau dimunculkan saat proses interaksi diskusi dalam pembelajaran, namun karena interaksi yang terjadi mengalami penurunan dalam esensi, maka pemahaman dan keyakinan peserta didik juga mengalami penurunan. Selain itu norma sosiomatematik yang dimiliki peserta didik sangat berpengaruh terhadap tinggi rendahnya hasil pemahaman yang di peroleh pada saat pembelajaran matematika berlangsung.

\section{REFERENSI}

A.B. Spierings, M. Voegtlin, T. Bauer, K. W. (2015). Case Study. Prog Addit Manuf, 1(10), 9-20.

Anisa, S., Supriadi, N., \& Pratiwi, D. D. (2019). Norma Sosiomatematik Ditinjau dari Minat Belajar Matematika Siswa peran penting dalam berbagai disiplin dan rasa ketertarikan pada suatu hal, tendency to pay attention to and enjoy kecenderungan yang tetap untuk pokok bagi siswa untuk berusaha dalam. 3(2), 153-164.

Aslamiah, H. (2018). Studi norma sosiomatematik dalam pembelajaran matematika.

Fatmawati. (2009). BAB_III E Fatmawati. 2013. Pendidikan Dan Kebudayaan, 5, 27-42. file:///D:/SRI AGUSTINA/Wisuda thn 2020, sidang tahap awal/wisuda 2020/1984.pdf

Fitriana, D. (2018). Peran Media E-Learning Dalam Pembelajaran Untuk Mengoptimalkan Kemampuan Literasi Matematika dan Norma Sosiomatematik. Prosiding Seminar Nasional "Penguatan Pendidikan Karakter Pada Siswa Dalam Menghadapi Tantangan Global,” 0291, 58-62.

Güven, N. D., \& Dede, Y. (2017). Examining social and sociomathematical norms in different classroom microcultures: Mathematics teacher education perspective. Kuram ve Uygulamada Egitim Bilimleri, 17(1), 265-292. https://doi.org/10.12738/estp.2017.1.0383

Kadir. (2008). Mengembangkan Norma Sosiomatematik (Sociomathematical Norms) Dengan Memanfaatkan Potensi Lokal Dalam Pembelajaran Matematika. Pythagoras : Jurnal Pendidikan Matematika, 4(1), 74-85. https://doi.org/10.21831/pg.v4i1.689

Muhaimin, M., \& Astuti, B. (2018). An Analysis of Sociomathematical Norms of Elementary School Students Through Collaborative Problem Solving Learning. Journal of Primary Education, 8(1), 67-74. https://doi.org/10.15294/jpe.v8i1.25232

Rijali, A. (2019). Analisis Data Kualitatif. Alhadharah: Jurnal Ilmu Dakwah, 17(33), 81. https://doi.org/10.18592/alhadharah.v17i33.2374

Rizkianto, I. (2013). Norma Sosiomatematik Dalam Kelas Matematika. Prosiding Seminar Nasional Matematika Dan Pendidikan Matematika, November, 978-979.

Sugiyono. (2016). Metode Penelitian Kuantitaif, kualitatif dan R\&D. Alfabeta.

Sulfikawati, D., Kurniati, D., Matematika, P., Keguruan, F., \& Unej, U. J. (2016). Analisis Norma Sosiomatematik dalam Pembelajaran Kolaboratif Pokok Bahasan Segitiga dan Segiempat di Kelas 
Analisis Sociomathematical Norms Peserta Didik dalam Pembelajaran Daring SMKN 39 Jakarta, Rizky Wahyu Maulana Salim $^{1}$, Samsul Ma'arif

VII-C SMP Negeri 11 Jember ( Sociomathematical Norms Analysis in Collaborative Learning in Triangle and Quadrilateral Topic at VII-C of Junior High . Jurnal Edukasi Unej, III(3), 1-4.

Utami, Y. P., \& Cahyono, D. A. D. (2020). Study At Home: Analisis Kesulitan Belajar Matematika Pada Proses Pembelajaran Daring. Jurnal Ilmiah Matematika Realistik, 1(1), 20-26. https://doi.org/10.33365/ji-mr.v1i1.252

Utari, R. S. (2017). Implementasi Nilai-Nilai Karakter dan Norma Sosiomatematik dalam Pembelajaran Matematika. Prosiding Seminar Nasional 20 Program Pascasarjana Universitas PGRI Palembang, November. https://www.kemdikbud.go.id/main/blog/2017/01/men

Widodo, S. A., \& Purnami, A. S. (2018). Mengembangkan Norma Sosiomatematik Dengan Team Accelerated Instruction. NUMERICAL: Jurnal Matematika Dan Pendidikan Matematika, 2(1), 29. https://doi.org/10.25217/numerical.v2i1.238

Zhafira, N. H., Ertika, Y., \& Chairiyaton. (2020). Persepsi Mahasiswa Terhadap Perkuliahan Daring Sebagai Sarana Pembelajaran Selama Masa Karantina Covid-19. Jurnal Bisnis Dan Kajian Strategi Manajemen, 4, 37-45. 